\title{
Raise taxes on high-alcohol products, British Columbia urged
}

Published at www.cmaj.ca on Dec. 24, 2009

$\mathrm{P}$ erhaps it was just bad timing. Recommending pricing changes to alcoholic beverages a few weeks before the Christmas holidays is unlikely to make people merry. Then again, academic theories about how pricing changes can curb excessive alcohol consumption are rarely met with enthusiasm by the public, according to Tim Stockwell, director of the Centre for Addictions Research of BC, which is located at the University of Victoria in British Columbia.

"I'm in awe of how controversial it is to say anything about our favourite recreational drug," says Stockwell.

Stockwell and colleages published a paper in December 2009 in which they suggest that the forthcoming introduction of a harmonized sales tax in British Columbia is a golden opportunity for the province to "strategically modify its pricing policies" for alcohol, which would "contribute significantly to the province's goal of becoming one of the healthiest jurisdictions in the world." (carbc.ca/portals/0/resources/AlcPricing \&HST.pdf)

The response has been overwhelmingly negative, says Stockwell. Callers to radio shows have referred to it as a government cash grab.

But nothing could be further from the truth, says Stockwell. The report doesn't recommend that the prices of all alcoholic beverages be increased. Rather, it proposes that the government create price disincentives for high-alcohol products that would be offset by price incentives for low-alcohol products.

"The existing tax structure shapes the existing market," he says. "You can play with that. You can have a revenueneutral solution that provides incentives for people to buy drinks that are less harmful to their bodies."

Between 1998 and 2008, alcohol consumption in BC rose $16 \%$ (from 7.5 litres to 8.7 litres per capita), while the overall Canadian increase was $9.3 \%$

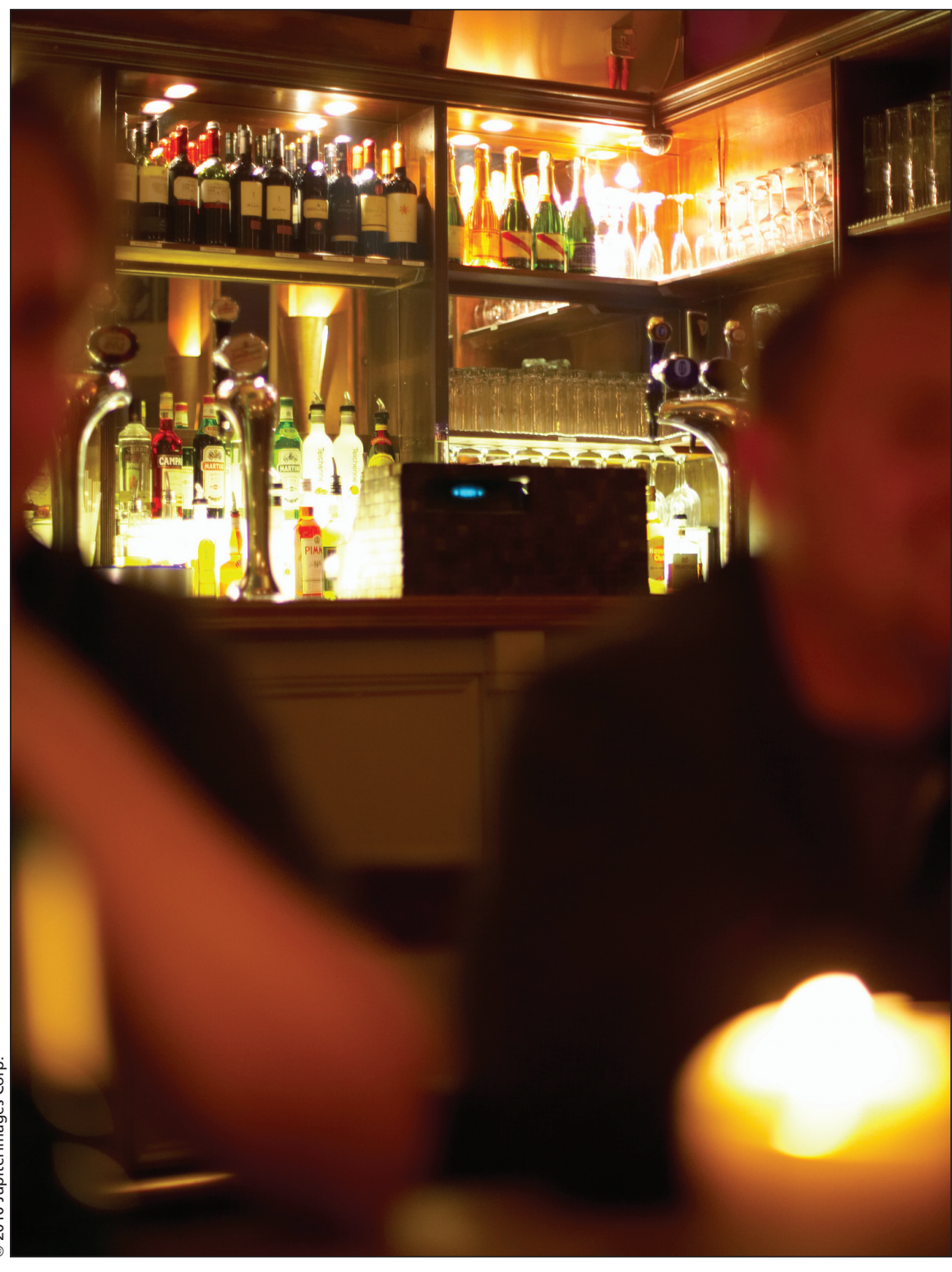

People should be given price incentives "to buy drinks that are less harmful to their bodies," argues Tim Stockwell, director of the Centre for Addictions Research of British Columbia.

(from 7.5 litres to 8.2 litres per capita). Stockwell attributes the steeper rise in $\mathrm{BC}$ to three factors: the rapid growth of wealth in the province; the failure of the government to adjust alcohol prices with inflation, and the huge increase in the number of private liquor stores, which have longer hours than most publicly owned stores.
The increased consumption of alcohol was accompanied by an increase in alcohol-related deaths and hospitalizations. Alcohol-related deaths rose $9.6 \%$ (from 1818 to 1993 ) between 2002 and 2007, according to the report. Deaths attributed to cirrhosis of the liver rose by $38.7 \%$ (from 271 to 376) - more than four times the 
increase in the rate of deaths from all causes.

These trends might be reversed, suggests Stockwell, if prices were based on alcohol content. In some beverage categories, such as coolers, drinks with high-alcohol content are often cheaper.

This is the opposite of the way it should be, as it encourages binge drinkers, who are often students, to load up on stronger beverages, says Stockwell. "They are getting drunk on a budget."

Making lower-strength beverages more affordable than high-alcohol drinks will increase their popularity, says Stockwell, citing the success of the Australian government in creating a market for low- to mid-strength beers. In the late 1980s, tax incentives were created to encourage the production of beers with $2.5 \%-3.8 \%$ alcohol. These beverages hadn't been popular before, but within a decade they comprised $40 \%$ of Australia's beer market (Int J Drug Policy 2001;12:139-52).

Other proposals in the report, which was submitted to the provincial cabinet, include setting "socially relevant" minimum prices for alcoholic beverages and increasing minimum prices according to inflation so alcohol doesn't continue to become cheaper compared to other goods.

Public health authorities have been supportive. Dr. Perry Kendall, British
Columbia's provincial health officer, said he made the same recommendations in his 2008 report Public Health Approach to Alcohol Policy (www .health.gov.bc.ca/library/publications /year/2008/alcoholpolicyreview.pdf).

"I am fully supportive as they are evidence-based recommendations," Kendall writes in an email.

But getting the provincial government onboard will be difficult, says Stockwell. In politics, it seems, the general attitude is: mess with booze, you lose. "I'm not confident that politicians will support it if it doesn't have public support." — Roger Collier, CMAJ

DOI:10.1503/cmaj.109-3141 